\title{
Isopropanol as Fuel for Small Unmanned Aircraft
}

\author{
Chung-How Poh, Chung-Kiak Poh \\ Aero-Persistence Research, Penang, Malaysia \\ Email: billy@aero-persistence.com
}

How to cite this paper: Poh, C.-H. and Poh, C.-K. (2017) Isopropanol as Fuel for Small Unmanned Aircraft. Advances in Aerospace Science and Technology, 2, 23-30. https://doi.org/10.4236/aast.2017.23003

Received: July 18, 2017

Accepted: August 25, 2017

Published: August 28, 2017

Copyright (C) 2017 by authors and Scientific Research Publishing Inc. This work is licensed under the Creative Commons Attribution International License (CC BY 4.0).

http://creativecommons.org/licenses/by/4.0/

\begin{abstract}
Gasoline engines are increasingly popular for use in small unmanned aircraft requiring endurance due to the specific energy of gasoline $\left(47.3 \mathrm{MJ} \cdot \mathrm{kg}^{-1}\right)$ and its cost effectiveness. However, gasoline is volatile and it poses a health hazard. In this work, isopropanol is proposed and investigated as viable fuel for small gasoline engines. Isooctane is used as a benchmark for performance comparison. The field testing reveals that isopropanol offers similar running performance and ease of starting. The maximum output power of isopropanol is surprisingly found to occur at a more advanced ignition timing compared with isooctane. The significant outcome of this study is that isopropanol can readily be used as a replacement fuel for existing engines without the need for any modifications to the ignition module or the engine itself.
\end{abstract}

\section{Keywords}

Isopropanol, Spark Ignition Engine, Small Unmanned Aircraft

\section{Introduction}

Unmanned aerial vehicles (UAVs) are becoming well-adopted for various civilian applications, particularly in the areas of aerial photography, inspections, land surveying and mapping [1]-[6]. Spark ignition (SI) gasoline engines are often the practical choice to power these UAVs that require flight endurance between 2 to 5 hours due to the following attributes: gasoline has a relatively high specific energy of $47.3 \mathrm{MJ} \cdot \mathrm{kg}^{-1}$, the affordability of gasoline fuel, and a wide selection of commercially available gasoline model engines with power density ranging approximately from 2.1 to $3.2 \mathrm{~kW} \cdot \mathrm{kg}^{-1}$ [7] [8].

However, besides from giving off a lingering petroleum odor [9], gasoline fuel and its exhaust residues present potential health hazards especially during engine tuning, trouble-shooting, transportation of the UAVs, manual refueling and 
storage. Engine carburetors and external fuel pumps are primary sources from which gasoline vapors enter the air and inhalation is a common route of exposure [10]. Gasoline vapors contain about $90 \%$ alkanes and $2 \%$ aromatics $(0.9 \%$ benzene) [10]. Moreover, gasoline may be carcinogen and many scientists believe there is no safe level of exposure to a carcinogen [9].

Alternative fuels include hydrogen and alcohols. Hydrogen has one of the highest specific energy contents $\left(141.86 \mathrm{MJ} \cdot \mathrm{kg}^{-1}\right)$ but being a gas at room temperature, hydrogen faces numerous challenges when it comes to practical implementations including safe storage, fitting the bulky pressurized storage tank within the limited space of a civilian UAV and a significantly lowered effective specific energy [11]. The first four aliphatic alcohols, namely methanol, ethanol, propanol and butanol are of interest as fuels because they can be synthesized chemically or biologically [12]. Furthermore, they have characteristics which allow them to be used in internal combustion engines [12]. Methanol is not suitable for endurance UAVs as it has only about half the energy density of gasoline and it is toxic [12]. Propanol and butanol are considerably less toxic and have significantly higher energy densities [12]. The specific energy contents of propanol and butanol are 33.4 and $36.1 \mathrm{MJ} \cdot \mathrm{kg}^{-1}$, respectively [13]. These attributes would make them potential fuels for endurance UAVs powered by SI engines where manual refueling process is required. Given the potentials of these fuels, ethanol, butanol and isopropanol blends have been extensively studied [14]-[19]. However, there has been very little study on the viability of isopropanol as neat fuel for SI engines.

In this work, we therefore proposed and investigated the use of isopropanol as neat fuel for SI engines to be used in endurance UAVs for civilian applications.

\section{Experimental Setup and Procedures}

The test engine used in this study was the Evolution ${ }^{\circledR} 10 \mathrm{GX}$ with a displacement of $10 \mathrm{cc}$ [20]. The original electronic ignition module that came with the engine was used for the field testing but the stock muffler was replaced by the more compact E-3071 from O.S. Engines for easier installation. A tachometer was connected to the ignition module to provide engine speed in real time. An adapter plate was designed and machined from a $5 \mathrm{~mm}$ birch plywood to enable the throttle servo (Hitec HS-82MG) to be placed in a more strategic position. The engine drove a Xoar $13 \times 6$ wooden propeller. The entire assembly was then mounted onto the firewall of a $20 \mathrm{cc}$ Yak 54 (Seagull Models) as shown in Figure 1. An external $12 \mathrm{~V}$ electric starter was used to start the engine by cranking on the spinner.

A small piece of magnet has been embedded into the engine drive hub (factory-assembled). The ignition module is triggered by the falling edge of the magnetic field. A Hall sensor was included with the engine and pre-installed close to the engine drive hub (Figure 2). A simple Arduino code was written to accurately detect the crank angle at which the falling edge occurred. With the help of 


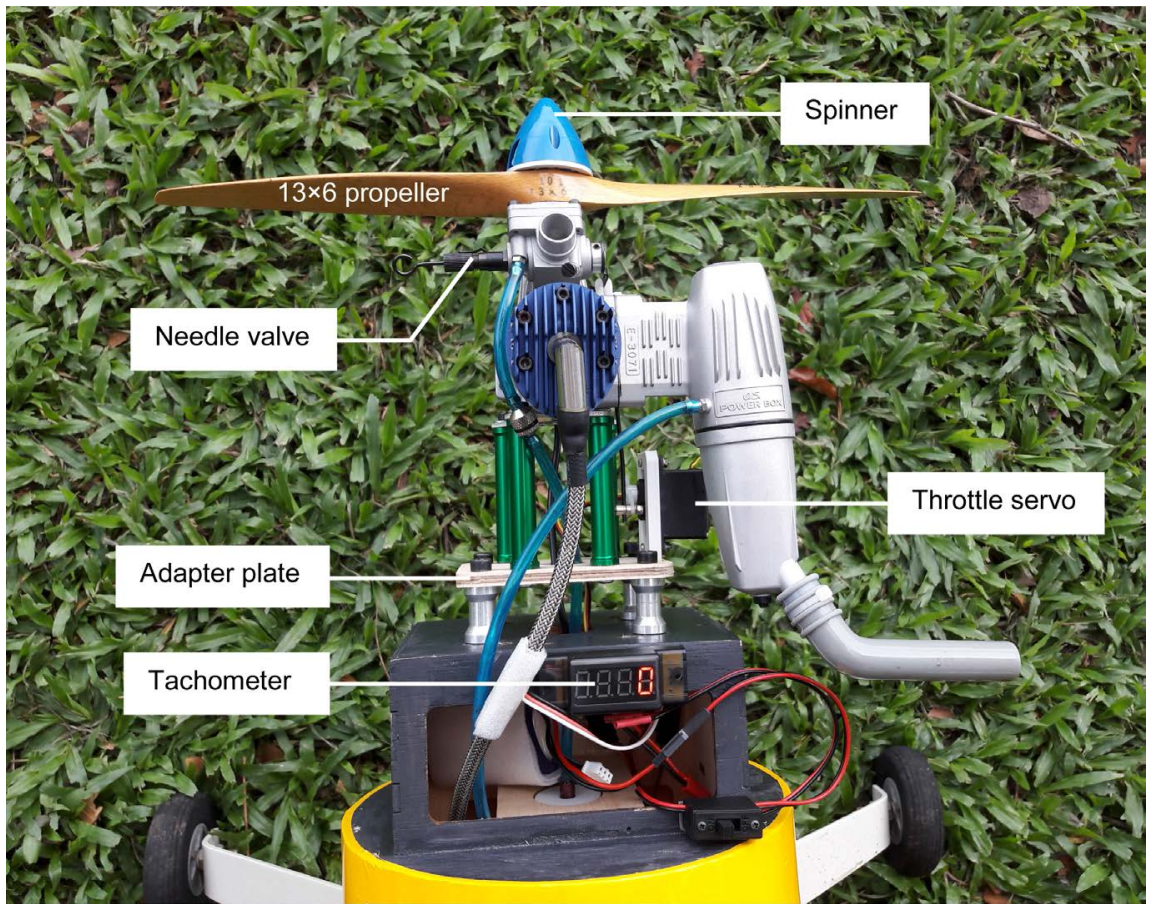

Figure 1. Experimental setup.

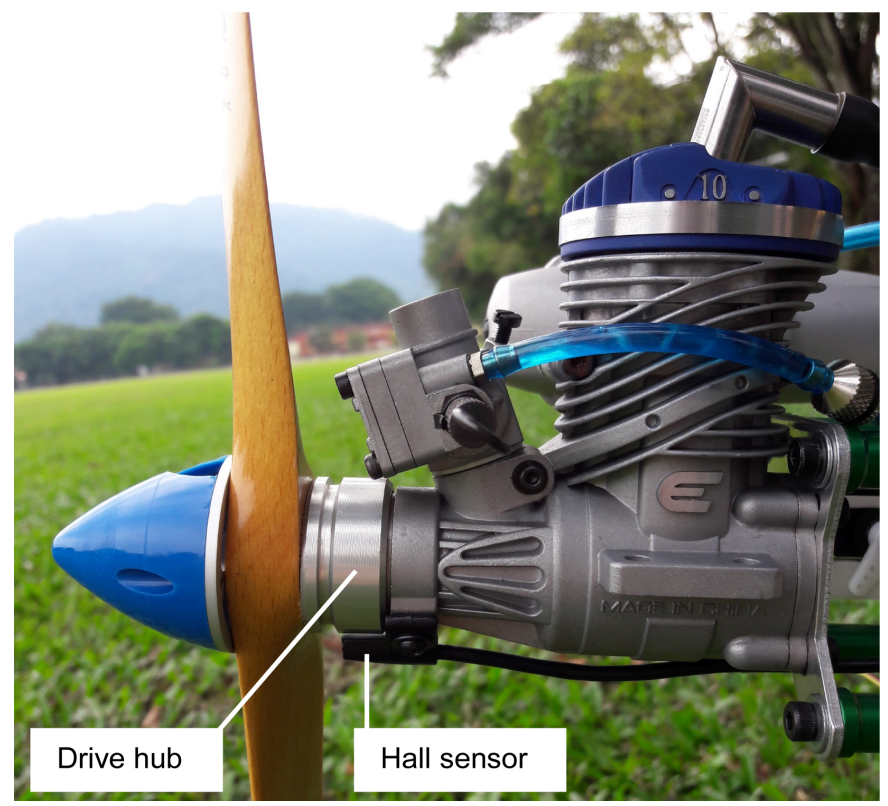

Figure 2. Side view of the engine showing the preset position of the Hall sensor.

a digital inclinometer, the spark plug was found to fire at crank angle (CA) $28^{\circ} \pm$ $0.5^{\circ}$ before top dead center (BTDC). The ignition position can be moved closer to the top dead center (TDC) by simply changing the position of Hall sensor (after loosening its 2 locking screws). The closest allowed position from TDC was measured to be $24^{\circ}$. Likewise, the Hall sensor may be slide in the opposite direction away from the TDC to fire the spark as early as $32^{\circ}$. A different Hall 
sensor with a custom mounting bracket would be installed if the required spark firing position exceeded $32^{\circ}$. It was expected that optimized ignition positions for the fuels could be found by varying the Hall sensor position in the range of $24^{\circ}$ to $32^{\circ}$ BTDC.

The GX10 manual recommends a minimum oil content of $4.8 \%(20: 1)$ premixed into its gasoline fuel [21]. Based on this guidance, a 5.0\% oil content (Klotz ${ }^{\circledR}$ TechniPlate ${ }^{\circledR}$ KL-200) was selected for premix into the isooctane. In the case of isopropanol, $4.0 \%$ oil content was used and this was derived by stoichiometry while ensuring the same amount of oil flowing through the engine at wide open throttle (WOT). Table 1 shows a summary of the fuel characteristics involved in this study [13] [22] [23].

Table 1. Fuel specifications.

\begin{tabular}{ccccccc}
\hline Fuel & Vendor & Grade & $\begin{array}{c}\text { Water } \\
(\%)\end{array}$ & $\begin{array}{c}\text { Density } \\
\left(\mathrm{g} \cdot \mathrm{cm}^{-3}\right)\end{array}$ & $\begin{array}{c}\text { Molecular mass } \\
\left(\mathrm{g} \cdot \mathrm{mol}^{-1}\right)\end{array}$ & $\begin{array}{c}\text { Specific energy } \\
\left(\mathrm{MJ} \cdot \mathrm{kg}^{-1}\right)\end{array}$ \\
\hline $\begin{array}{c}\text { Isooctane } \\
\text { Isopropanol }\end{array}$ & Fisher Scientific & F.R. & 0.01 & 0.690 & 114.23 & 47.9 \\
\hline
\end{tabular}

\section{Results and Discussion}

The engine was found to start easily with the isopropanol fuel at field temperature of $30^{\circ} \mathrm{C}$ in shade. It started within 1.5 seconds when cranked using the external electric starter and the ease of starting was similar to that of isooctane. However, being an alcohol fuel, some heating might be required for ease of starting in colder weathers. Once the engine has warmed up, the engine was tuned at WOT for maximum engine speed (and hence peak output power). With the Hall sensor at preset position, the optimal settings of the needle valve for the isooctane and isopropanol were approximately 1.13 and 2.38 turns, respectively and this was consistent with the fact that isooctane has higher energy density than isopropanol. The engine running on isopropanol was found to have steady idle and excellent throttle response. A short video showing the throttle response is available as Video 1. Figure 3 is a snapshot showing the test engine running at 2800 RPM on isopropanol.

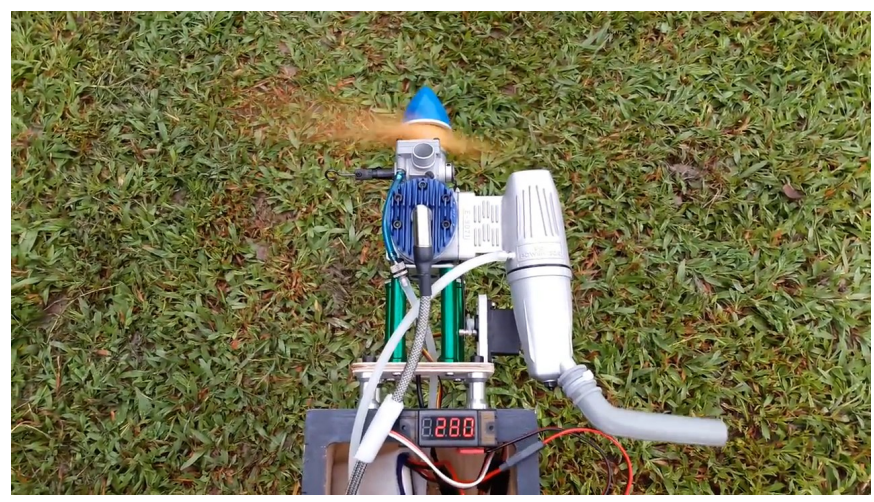

Figure 3. The test engine running on isopropanol. 
The Hall sensor position was then varied to determine the optimal timing. For each sensor position, the needle valve was fine-tuned at WOT to ensure the maximum engine speed has been correctly obtained. It was observed that the needle valve was largely unaffected by the change of the ignition position. The collected results were as presented in Figure 4. The maximum engine speeds obtained were used to generate calculated static thrusts [24]. In the calculations, the local altitude was entered as $15 \mathrm{~m}$ above sea level and custom propeller type was selected, with $K_{t}=0.81$ and $K_{p}=0.69$. The calculated static thrusts were shown in Figure 5. At maximum engine speed, both isooctane and isopropanol produced comparable static thrust. The data in Figure 4 indicate that the isooctane achieved a maximum speed of $9260 \mathrm{RPM}$ at $30^{\circ} \pm 1^{\circ}$ BTDC and this optimal

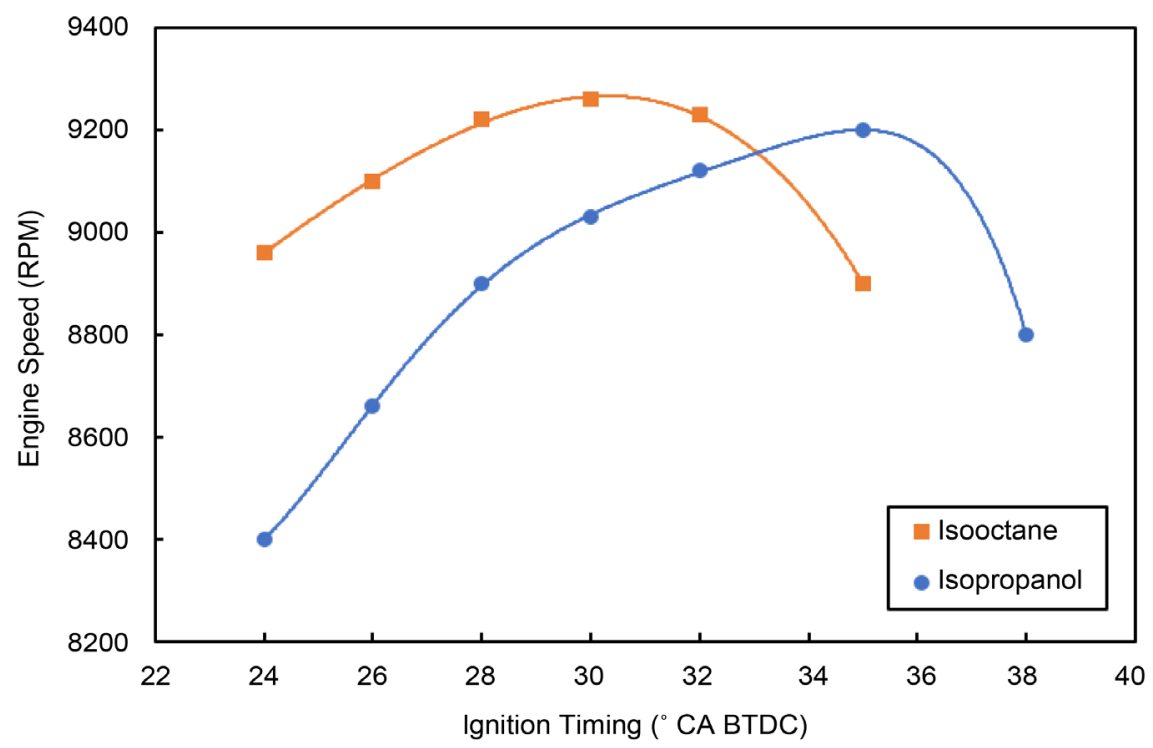

Figure 4. Maximum engine speed as a function of ignition position for both fuels.

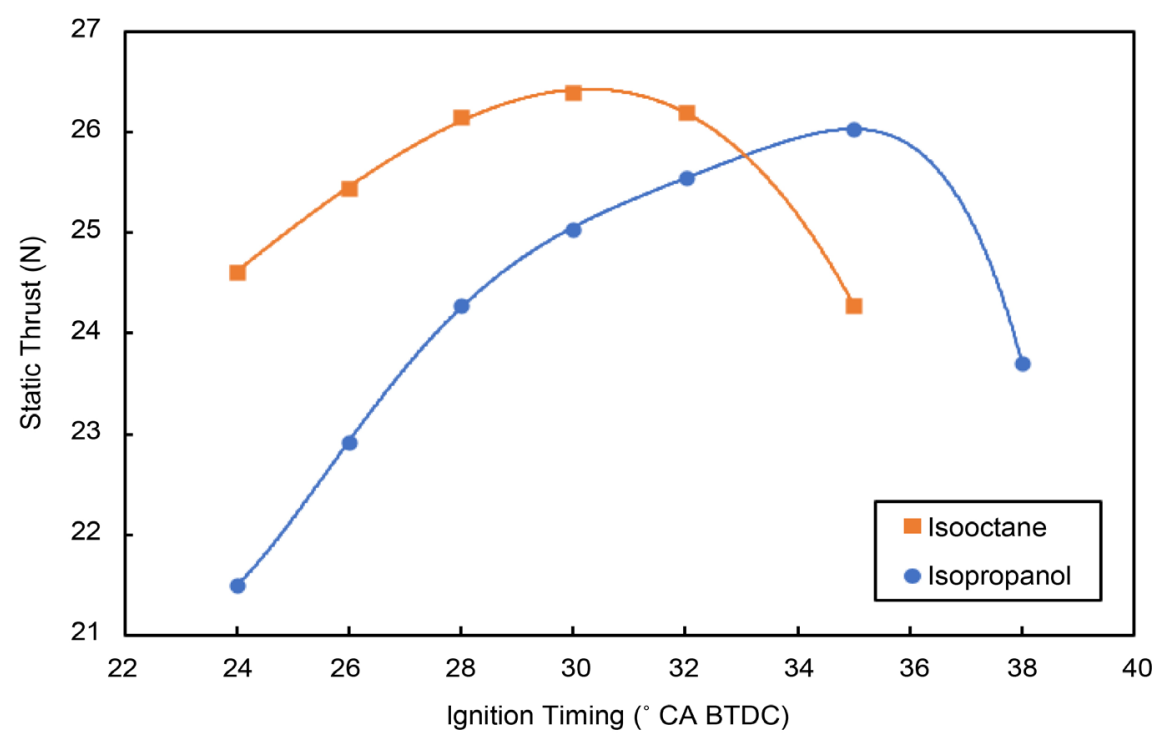

Figure 5. The corresponding calculated static thrusts produced by the propeller. 
timing was in excellent agreement with the value reported in the literature [25]. The isopropanol achieved a similar maximum speed of 9200 RPM but at a more advanced timing of $35^{\circ}$ BTDC. It has been widely reported that, in general, alcohols have faster flame propagation speeds compared to isooctane [26] [27]. It was therefore a surprise that the isopropanol demonstrated a need for its ignition position to be advanced, rather than retarded.

A plausible explanation for the unexpected result might be related to the effect of cylinder pressure on the flame propagation speed. It has been shown that under laminar conditions, the flame propagation speed of isooctane slowed with increasing cylinder pressure [28]. It is therefore possible that isopropanol exhibits greater sensitivity to increased cylinder pressure resulting in a significantly slower flame propagation speed compared to isooctane. Nevertheless, future work involving realistic in-cylinder conditions is needed to ascertain the exact mechanisms leading to isopropanol having a more advanced ignition timing.

\section{Conclusion}

This study proposed and investigated isopropanol as a potential neat fuel for endurance UAVs. Field testing using a commercially available gasoline engine with its stock ignition module revealed that the isopropanol fuel resulted in steady reliable idle, in addition to excellent throttle response. Furthermore, the $10 \mathrm{cc}$ test engine powered by isopropanol started within 1.5 seconds when cranked with external electric starter. The maximum output power at an ignition timing of around $35^{\circ} \mathrm{CA} \mathrm{BTDC}$ was on par with that of isooctane. The significance of this study is that, apart from shifting the Hall sensor to a more advanced position, isopropanol can readily be used as an alternative fuel to gasoline which contains potentially carcinogenic components. This will bring enormous health benefits to operators of gasoline powered civilian UAVs that often require manual refueling. Use of isopropanol will also mitigate the issues of indirect exposures to gasoline fumes and exhaust residues during regular maintenance and transportation of the UAVs. The detailed mechanisms that led to isopropanol requiring a more advanced ignition timing at wide open throttle compared with isooctane will be the subject of future study.

\section{References}

[1] Khan, S., Aragão, L. and Iriarte, J. (2017) A UAV-Lidar System to Map Amazonian Rainforest and Its Ancient Landscape Transformations. International Journal of Remote Sensing, 38, 2313-2330.

[2] Salamí, E., Barrado, C. and Pastor, E. (2014) UAV Flight Experiments Applied to the Remote Sensing of Vegetated Areas. Remote Sensing, 6, 11051-11081. http://dx.doi.org/10.3390/rs61111051

[3] UAV Factory (2017) UAV28-EFI System. http://www.uavfactory.com/product/77

[4] SUAS News (2015) GAUI GX9 Helicopter Test Flight. https://www.suasnews.com/2015/07/gaui-gx9-helicopter-test-flight/

[5] Blain, L. (2017) SOAPdrones Variable Pitch Quadcopter Uses Petrol Power for 
Heavy-Lifting Endurance.

http://newatlas.com/soapdrones-variable-pitch-multirotor-endurance/48202/

[6] Yamaha RMAX (2013) Yamaha Unmanned Helicopters Are Designed for a Wide Range of Industrial and Research Applications. http://rmax.yamaha-motor.com.au

[7] Hobbico (2017) O.S. GGT 10 Gasoline Engine. http://www.osengines.com/engines-airplane/osmg1510/index.html

[8] RCGF USA (2014) RCGF 120cc Twin. https://www.rcgfusa.com/rcgf-120-t-2

[9] New Jersey Department of Health (2016) Hazardous Substance Fact Sheet. http://nj.gov/health/eoh/rtkweb/documents/fs/0957.pdf

[10] Agency for Toxic Substances and Disease Registry (2014) Medical Management Guidelines for Gasoline.

https://www.atsdr.cdc.gov/MMG/MMG.asp?id=465\&tid=83

[11] Sankir, M. and Sankir, N.D. (2017) Hydrogen Production Technologies. Scrivener Publishing, Beverly. https://doi.org/10.1002/9781119283676

[12] Wikipedia (2017) Alcohol Fuel. https://en.wikipedia.org/wiki/Alcohol_fuel

[13] Neutrium (2014) Specific Energy and Energy Density of Fuels. https://neutrium.net/properties/specific-energy-and-energy-density-of-fuels/

[14] Sivasubramanian, H., Pochareddy, Y.K., Dhamodaran, G. and Esakkimuthu, G.S. (2017) Performance, Emission and Combustion Characteristics of a Branched Higher Mass, C3 Alcohol (Isopropanol) Blends Fuelled Medium Duty MPFI SI Engine. Engineering Science and Technology, an International Journal, 20, 528-535. https://doi.org/10.1016/j.jestch.2016.11.013

[15] Serras-Pereira, J., Aleiferis, P.G. and Richardson, D. (2013) An Analysis of the Combustion Behavior of Ethanol, Butanol, Iso-Octane, Gasoline, and Methane in a Direct-Injection Spark-Ignition Research Engine. Combustion Science and Technology, 185, 484-513. http://dx.doi.org/10.1080/00102202.2012.728650

[16] Beeckmann, J., Cai, L. and Pitsch, H. (2013) Experimental Investigation of the Laminar Burning Velocities of Methanol, Ethanol, N-Propanol, and N-Butanol at High Pressure. Fuel, 117, 340-350. https://doi.org/10.1016/j.fuel.2013.09.025

[17] Moxey, B.G., Cairns, A. and Zhao, H. (2016) A Comparison of Butanol and Ethanol Flame Development in an Optical Spark Ignition Engine. Fuel, 170, 27-38. https://doi.org/10.1016/j.fuel.2015.12.008

[18] Li, Y., Meng, L., Nithyanandan, K., Lee, T.H., Lin, Y., Lee, C.F. and Liao, S. (2016) Combustion, Performance and Emissions Characteristics of a Spark-Ignition Engine Fueled with Isopropanol-N-Butanol-Ethanol and Gasoline Blends. Fuel, 184, 864-872. https://doi.org/10.1016/j.fuel.2016.07.063

[19] Mack, J.H., Schuler, D., Butt, R.H. and Dibble, R.W. (2016) Experimental Investigation of Butanol Isomer Combustion in Homogeneous Charge Compression Ignition (HCCI) Engines. Applied Energy, 165, 612-626. https://doi.org/10.1016/j.apenergy.2015.12.105

[20] Horizon Hobby, LLC (2017) Evolution ${ }^{\circledR}$ 10GX Engine. http://www.evolutionengines.com/Products/Default.aspx?ProdID=EVOE10GX

[21] Horizon Hobby, LLC (2013) User Manual for Evolution ${ }^{\circledR}$ 10GX Engine. http://www.evolutionengines.com/ProdInfo/Files/EVOE10GX_Manual.pdf

[22] Fisher Scientific UK Limited (2017) Isopropanol, Certified AR for Analysis. https://www.fishersci.co.uk/shop/products/isopropanol-certified-ar-analysis-2/1031 $\underline{5720}$ 
[23] Fisher Scientific UK Limited (2017) 2, 2, 4-Trimethylpentane, 99.5\%, for Analysis. https://www.fishersci.co.uk/shop/products/2-2-4-trimethylpentane-99-5-analysis-ac ros-organics-4/10551111

[24] One, A. (2016) Estimation of Propeller's Static Thrust. http://rcplanes.000webhostapp.com/calc_thrust.htm

[25] Kakaee, A.H., Shojaeefard, M.H. and Zareei, J. (2011) Sensitivity and Effect of Ignition Timing on the Performance of a Spark Ignition Engine: An Experimental and Modeling Study. Journal of Combustion, 2011, Article ID: 678719. http://dx.doi.org/10.1155/2011/678719

[26] Aleiferis, P.G. and Behringer, M.K. (2015) Flame Front Analysis of Ethanol, Butanol, Iso-Octane and Gasoline in a Spark-Ignition Engine Using Laser Tomography and Integral Length Scale Measurements. Combustion and Flame, 162, 4533-4552. https://doi.org/10.1016/j.combustflame.2015.09.008

[27] Li, Q., Jin, W. and Huang, Z. (2016) Laminar Flame Characteristics of C1-C5 Primary Alcohol-Isooctane Blends at Elevated Temperature. Energies, 9, 511. http://dx.doi.org/10.3390/en9070511

[28] Byun, J.J. (2011) Laminar Burning Velocities and Laminar Flame Speeds of Multi-Component Fuel Blends at Elevated Temperatures and Pressures. Ph.D. Thesis, the University of Texas at Austin, Austin. http://hdl.handle.net/2152/ETD-UT-2011-05-516

\section{Submit or recommend next manuscript to SCIRP and we will provide best service for you:}

Accepting pre-submission inquiries through Email, Facebook, LinkedIn, Twitter, etc. A wide selection of journals (inclusive of 9 subjects, more than 200 journals) Providing 24-hour high-quality service User-friendly online submission system Fair and swift peer-review system Efficient typesetting and proofreading procedure Display of the result of downloads and visits, as well as the number of cited articles Maximum dissemination of your research work

Submit your manuscript at: http://papersubmission.scirp.org/

Or contact aast@scirp.org 